\title{
AgnieszKa KaCPRZAK
}

\author{
Uniwersytet Technologiczno-Humanistyczny \\ im. Kazimierza Pułaskiego w Radomiu
}

\section{LA REGOLA 'PACTA SUNT SERVANDA' E LA NASCITA DELLA LIBERTÀ CONTRATTUALE}

Regole giuridiche provenienti dalla codificazione giustinianea e reinterpretate dai giuristi delle epoche successive, sono spesso state veicolo per lo sviluppo del diritto e della scienza giuridica. Non di rado, tale sviluppo è stato determinato dall'interpretazione 'creativa' di dette regole che nei casi limite poteva portare perfino al rovesciamento del loro significato originale.

In alcuni casi, tuttavia, le regole nate nel diritto romano e trasmesse nel Corpus giustinianeo si sono rivelate una specie di ostacolo, creando per la giurisprudenza legata alla tradizione romanistica delle difficoltà nel riconoscere idee nuove, contrastanti con questa tradizione. Così avvenne con il principio di non azionabilità dei pacta nuda, richiamato da Ulpiano nel D.2,14,7,4: nudum pactum actionem non parit sed parit exceptionem. Il testo ulpianeo è stato richiamato come argomento contro il riconoscimento della libertà contrattuale nel diritto civile sia dai giuristi medievali, che dagli ultimi opponenti di essa nel secolo sedicesimo, come Covarrubias in Spagna o Connan in Francia ${ }^{1}$ (v. infra).

1 Cfr. W. Decock, Theologians and Contract Law. The Moral Transformation of the Ius Commune (ca. 1500-1650), Leiden-Boston 2013, pp. 115-121, dove l'autore presenta pure le prese di posizione dei umanisti francesi, Cujas and Doneau, difendenti anche loro la purità della dottrina romana della non azionabilità dei pacta nuda. 
Il principio della libertà contrattuale, il quale sarà riconosciuto in modo pressoché unanime nella scienza giuridica del seicento, trova la sua espressione più concisa nel broccardo pacta sunt servanda, nato nell'ambito del diritto canonico ${ }^{2}$. Lo troviamo infatti, per la prima volta così formulato, nel Liber Extra dell'anno 1234, e cioè come titolo al canone Antigonus. Il canone stesso è molto più risalente, in quanto nasce dalla decisione del sinodo di Carthago dell'anno 348, il quale obbligò il vescovo Optantius a rispettare il patto, concluso con il vescovo Antigonus, circa i confini tra le loro diocesi. Nonostante la decisione del sinodo presupponga il riconoscimento della forza vincolante dell'accordo tra i due vescovi, bisogna sottolineare che siamo ancora molto lungi dall'agnizione dell'obbligatorietà dei pacta come un principio generale nel diritto canonico ${ }^{3}$.

Il primo tentativo di giustificare il carattere vincolante delle promesse informali nell'ambito del diritto canonico precede tuttavia la formulazione del broccardo, siccome proviene dalla glossa al canone Quicumque suffragio di Uguccione da Pisa, contenuta nella Summa ai decreti di Graziano dell'anno 1188 (ragion per cui alcuni studiosi indicano proprio quest'anno coma la data di nascita del principio pacta sunt servanda) ${ }^{4}$.

2 Riguardo alla categoria dei pacta nuda nel diritto canonico, v. P. FEDELE, Considerazioni sull'efficacia dei patti nudi nel diritto canonico, "Annali dell'Università di Macerata»1937, pp. 115-120.

3 A. Söllner, Die causa in Kondiktionen- und Vertragsrecht des Mittelalters bei den Glossatoren, Kommentatoren und Kanonisten, «ZSS» 77/1960, pp. 240-241, punta sul fatto che l'accordo tra i due vescovi aveva la forma scritta e sostiene che si trattava di un contratto valido secondo il diritto romano vigente all'epoca nella parte occidentale dell'impero romano. Nella formulazione trasmessa nei Decreti di Graziano il riferimento alla scrittura viene eliminato, probabilmente con lo scopo di esaltare il principio della forza vincolante degli accordi, a prescindere dalla loro forma. Del riconoscimento del principio pacta sunt servanda nel diritto canonico si può parlare a partire dall'introduzione degli mezzi della tutela, quali condictio ex canone iuramenti e denuntiatio evangelica nel tredicesimo secolo, v. infra. L'esistenza del principio generale dell'efficacia dei pacta nuda del diritto canonico è stata messa in discussione da G. Astuti, Contratto (diritto intermedio), «ED» 9/1961, p. 775 e da P. Fedele, op. cit., pp. 115-120.

4 Così P. Landau, 'Pacta sunt servanda'. Zu den kanonistischen Grundlagen der Privatautonomie, [in:] Festschrift Knut Wolfgang Nörr, ed. M. Ascheri, F. Ebel, M. 
Il canonista Bolognese sostiene che rompere una promessa, anche se informale, è un peccato equivalente a quello di rompere un giuramento, perché Dio non vuole che vi sia alcuna differenza tra il giuramento e la semplice promessa. La giustificazione di Uguccione da Pisa rimane interamente legata ai principi teologici ${ }^{5}$, mentre la formulazione del titolo del canone Antigonus: "pacta, quantumque nuda, servanda sunt", rinvia alla categoria romana dei pacta nuda, sviluppata dai glossatori e integrata con il concetto complementare dei pacta vestita (v. infra).

Il riconoscimento dell'obbligatorietà dei pacta sarebbe rimasto una lettera vuota senza i mezzi di tutela, atti a forzare il loro adempimento. Con quest'ultimo problema si sono confrontati da un lato il canonista Giovanni Teutonico (morto 1245), e dall'altro il papa Innocenzio IV (eletto 1243). A tal fine, il primo ha proposto l'applicazione della condictio ex canone iuramenti (modellata sulla condictio ex lege del diritto civile, applicabile a tutela dei pacta legitima $)^{6}$, così estendendo la tutela dei giuramenti alle promesse informali (in conformità con l'dea dell'equivalenza tra i giuramenti e le promesse semplici, postulata nella glossa di Uguccione da Pisa). Tra i canonisti la sua proposta è stata quasi unanimemente accolta ${ }^{7}$. Il limite della soluzione del Teutonico consisteva però nel fatto che era possibile applicarla solo nell'ambito della giurisdizione della Chiesa. Più vantaggiosa da questo punto di vista era la proposta del papa, ossia l'applicazione della denuntiatio evangelica contro coloro che non avrebbero adempiuto alle proprie promesse. Si tratta di un mezzo correttivo che ogni cristiano poteva - e doveva - applicare contro

Heckel, Weimar 2003, pp. 464-467. Secondo H. Dilcher, Der Typenzwang im mittelalterlichen Vertragsrecht, «ZSS»77/1960, pp. 283-284, di un tale riconoscimento si può parlare soltanto a partire dal Giovanni Teutonico, discepolo di Azzone. Dilcher punta sul fatto che ancora Bernardo di Pavia - un discepolo di Uguccione - non riconosceva l'obbligatorietà dei pacta nuda.

5 Cfr. W. Decock, op. cit., pp. 123-124.

6 K.P. NANZ, Die Entstehung des allgemeinen Vertragsbegriffs im 16 bis 18 Jahrhundert, München 1985, p. 53. Giovanni Teutonico si richiama al testo del vescovo di Acquileia, Chromatius, il quale commentava il Vangelo secondo Matteo. Teutonico interpreta il termine loquela (discorso, il detto), come l'accordo, dando così al testo del vescovo significato tecnico-giuridico (K.P. NANZ, op., cit., p. 48).

$7 \quad$ K.P. Nanz, op. cit., p. 53-54; W. Decock, op. cit., p. 127. 
il peccatore: ammonendolo prima individualmente, poi in presenza degli altri, ad abbandonare il peccato. La procedura poteva concludersi perfino con la scomunica, se il peccatore avesse persistito nel peccato nonostante le ammonizioni ulteriori davanti la comunità ${ }^{8}$. Denuntiatio evangelica poteva servire come un mezzo di pressione, volto a portare il promettente all'adempimento della promessa, se questi però resisteva, dal punto di vista del promissario questa non si dimostrava essere soluzione utile: dalla scomunica del debitore egli non traeva infatti alcun vantaggio. Come giustamente osservato da Nanz, l'efficacia di tale mezzo di pressione dipendeva in fin dei conti dall'atteggiamento personale del promittente: se egli non temeva la scomunica, poteva benissimo rimanere inadempiente ${ }^{9}$. Se si pensa però, che la possibilità di garantire le promesse fatte in favore della Chiesa fosse uno dei motivi importanti per cui i canonisti insistevano sull'obbligatorietà dei pacta nel diritto canonico, come lo stesso Nanz osserva altrove ${ }^{10}$, l'efficacia del mezzo in questione si mostra ben plausibile. Inoltre, la denuntiatio presentava l'indubbio vantaggio di essere applicabile contro ogni promittente di fede cattolica. I due mezzi di tutela potevano quindi benissimo coesistere, come ha osservato Baldus: il primo nei confronti dei membri del clero e dei laici suddetti alla giurisdizione della chiesa, il secondo contro tutti gli altri seguaci della fede cattolica ${ }^{11}$.

Come si evince da quanto detto sopra, il termine pactum nel linguaggio dei canonisti si riferisce ad una promessa unilaterale informale, a differenza del giuramento (oppure del voto) che costituisce

8 K.P. NAnz, op. cit., p. 53. Sulla denuntiatio evangelica, v. anche A. SöLlner, op. cit., pp. $245-246$.

9 K.P. NANZ, op. cit., p. 53: „Diese Methode versprach freilich nur dann Erfolg, wenn der wortbrüchige Schuldner die Exkommunikation als drohendes Übel empfand und sie durch Leistung des Versprochenen abzuwenden bereit war. Ließ sie den Schuldner jedoch kalt, war dem Gläubiger nicht geholfen“.

10 K.P. NAnZ, op. cit., p. 60, punta sui voti, fatti in favore della Chiesa nelle diverse situazioni di pericolo. La possibilità di garantire l'adempimento di tali promesse doveva essere certo una delle preoccupazioni della Chiesa, accanto a quella di salvaguardare la condotta morale della gente.

11 Baldus de Ubaldis, 'Commentaria in primam digesti veteris partem', Lugdunum 1585. In C.4,32,16, n. 16 (f.107 r.), cfr. K.P. NANZ, op. cit., p. 55. 
una promessa unilaterale formale, ossia solenne ${ }^{12}$. Si fa notare la corrispondenza con la riflessione dei civilisti che in maniera analoga intendono la stipulatio come una specie del pactum, reso azionabile attraverso la forma solenne (e quindi un pactum vestitum). (I civilisti rimangono però fedeli al dogma della non-azionabilità delle promesse informali, ossia dei pacta, nel diritto civile. Bisogna sottolineare però che anche i canonisti limitavano il postulato dell'azionabilità dei pacta al solo diritto canonico, riconoscendo invece la loro inefficacia iure civili, in sintonia con i civilisti).

Nel pensiero degli studiosi del diritto civile, dei glossatori e dei commentatori, il termine pactum tende ad assumere il significato generale, atto a comprendere tutti i contratti, a prescindere sia dalla loro struttura che dal loro essere azionabili o meno ${ }^{13}$. Lo si evince dalla dottrina dei vestimenta pactorum (v. infra).

Cruciali per la riflessione dei glossatori e dei commentatori sul rapporto tra pactum, conventio e contractum sono i brani D. 2,14,7pr. -2 e 4 del Digesto $^{14}$. Si tratta di una parte del commento di Ulpiano all' edictum de pactis (libro quarto del suo commentario ad Edictum). Ulpiano parte dalla divisione delle convenzioni provenienti dal ius gentium tra quelle che danno luogo all'azione, e quelle che permettono soltanto di sollevare l'eccezione contro una pretesa altrui: Iuris gentium conventiones quaedam actiones pariunt, quaedam exceptiones (D. 2,14,7pr.). Nella prima categoria rientrano i contratti nominati (D. 2,14,7,1) ${ }^{15}$, nonché innominati, basati sullo schema do ut des et do ut facias, definiti come

12 H. Dilcher, op. cit., pp. 282-283, punta sul fatto che la glossa di Uguccione, considerata come il germe della dottrina sulla forza vincolante dei pacta nuda nel diritto canonico, si riferisce ad una promessa unilaterale.

13 A. Söllner, op. cit., p. 216.

14 Cfr. R. Volante, Il sistema contrattuale del diritto comune classico. Struttura dei patti e individuazione del tipo. Glossatori e Ultramonatni, Milano 2001, p. 50.

15 Quae pariunt actiones, in suo nomine non stant, sed transeunt in proprium nomen contractus: ut emptio venditio, locatio conductio, societas, commodatum, depositum, et ceteri similes contractus. La circostanza che Ulpiano elenca soltanto i contratti, dai giuristi romani ritenuti iuris gentium, omettendo invece mandatum, mutuum e stipulatio, si spiega con il fatto che sta parlando, appunto delle convenzioni iuris gentium. A quali contratti invece si riferisce la frase 'altri simili' non è del tutto chiaro, ma è possibile 
quelli che hanno causa (D. $2,14,7,2)^{16}$. La seconda categoria, quella delle convenzioni non azionabili, comprende invece quelle che non hanno né nomen, né causa, e che sono equiparate ai pacta: Sed cum nulla subest causa, propter conventionem hic constat non posse constitui obligationem: igitur nuda pactio obligationem non parit, sed parit exceptionem (D. $2,14,7,4)$. Nel commento ulpianeo quindi la nozione di conventio funge del termine generale che comprende da un lato le convenzioni azionabili secondo il ius civile, ossia i contratti nominati e innominati reali, che quelle non azionabili, ossia tutte le altre convenzioni che non adempiono né al requisito di nomen, né a quello di causa (pacta nuda) ${ }^{17}$. Il significato generale del termine conventio è ancora più accentuato in un altro frammento proveniente dallo stesso libro del commento di Ulpiano ad Edictum:

D. 2,14,1,3: Conventionis verbum generale est ad omnia pertinens, de quibus negotii contrahendi transigendique causa consentiunt qui inter se agunt: nam sicuti convenire dicuntur qui ex diversis locis in unum locum colliguntur et veniunt, ita et qui ex diversis animi motibus in unum consentiunt, id est in unam sententiam decurrunt. Adeo autem conventionis nomen generale est, ut eleganter dicat Pedius nullum esse contractum, nullam obligationem, quae non habeat in se conventionem, sive re, sive verbis fiat: nam et stipulatio, quae verbis fit, nisi habeat consensum, nulla est. 4. Sed conventionum pleraeque in aliud nomen transeunt: veluti in emptionem, in locationem, in pignus vel stipulationem.

Il termine conventio, piuttosto che al contratto per intero, questa volta sembra riferirsi in particolare al consenso, sottostante ogni contratto: Ulpiano riporta qui l'opinione di Pedio, dando l'impressione di seguire il pensiero del giurista del principato. L'accentuazione del consenso in quanto elemento indispensabile per ogni contratto attira particolarmente

che si tratti dei contratti iuris civilis, simili agli elencati proprio in quanto nominati, ma diversi perché non provenienti dal ius gentium.

16 Si tratta dei contratti reali innominati.

17 A. Söllner, op. cit., p. 214, sostiene che il testo del D. 2,14,7, così come trasmesso nel Digesto, ossia incentrato sull'idea del consenso come l'essenza del contratto, rispecchia la teoria bizantina del contratto. 
l'attenzione dei giuristi medievali che sviluppano su quelle basi il concetto del consenso come sostanza del contratto ${ }^{18}$. In consonanza al D. 2,14,7,4 escludono però che il solo consenso sia sufficiente per rendere un contratto azionabile iure civili, insistendo sulla necessità degli elementi ulteriori a tal uopo: tali elementi sarebbero individuabili in tutti i contratti nominati, nonché innominati reali e vengono denominati, per contrapposizione alla 'nudità' del pactum non azionabile, come vestimenta (v. infra).

Il fatto che i glossatori scelgano come loro termine generale per i contratti la nozione di pactum, piuttosto di conventio, nonostante quest'ultima sarebbe più consone al testo di Ulpiano ${ }^{19}$, può sorprendere.

Tale scelta trova riscontro nei tre brani dal commento di Ulpiano ad Edictum: nel D. 2,14,7,4 il termie pactum viene equiparato alla conventio, e quindi alla nozione che Ulpiano utilizza in riferimento a tutti i contratti (D. 2,14,7,2). Nel D. 2,14,1,2 pactum viene descritto come il consenso tra più persone: Et est pactio duorum pluriumve in idem placitum et consensus (cfr. anche D. 2,14,1,120). Nel D. 2,14,1,3 infine conventio diventa il sinonimo del consensus. Se il pactum corrisponde a conventio, ossia è il prodotto del consenso tra più persone, allora i due termini possono essere visti come i sinonimi. Riferendosi all'ultimo testo, Azzone spiega che il termine conventio è troppo generale, perché si riferisce ad ogni tipo di raduno tra diverse persone, anche se non hanno l'intenzione di stringere alcuna obbligazione (p.e. discepoli che si radunano, conveniunt, nella scuola), mentre il pactum significa proprio l'agire con lo scopo di

18 A. Söllner, op. cit., pp. 216-217: “Die Glossatoren entnahmen jedoch dem Corpus Iuris, dass alle obligatorischen Verträge eine willensmäßige Übereinstimmung zur Voraussetzung haben, und folgerten deshalb aus D. 2,14,1,1, dass pactum der Oberbegriff für alle obligatorischen Verträge einschließlich Stipulation sei“.

19 Come giustamente osserva A. Söllner, op. cit., p. 216, nel testo ulpianeo la nozione di conventio, piuttosto che quella di pactum, viene usata come il termine generale per tutti i contratti: "Der gemeinsame Oberbegriff für alle obligatorischen Verträge war in ihren Augen nicht etwa conventio, wie man angesichts D. 2,14,1,3 und 4, und D. 2,14,7 annehmen sollte, sondern das Wort pactum, wie es in der Ulpianstelle D. 2,14,1,1 definiert ist“.

20 D. 2,14,1,1: Pactum autem a pactione dicitur (inde etiam pacis nomen appellatum est). 
stringere un'obbligazione: Est hec nomen pactum generale ad omnia quae aguntur inter partes causa obligationis contrahendae vel tolliendae. Nomen vero conventionis generalissimus est. Nam et scholares dicuntur convenire in scholiis et quilibet alii in quemvis alium locum, licet inter se non obligentur ${ }^{21}$. Per questa ragione pactum gli pare più adatto come termine generale comprendente tutti i contratti. Va inoltre notato che tale scelta è conforme al linguaggio del diritto canonico (v. supra).

Come è stato già menzionato sopra, la non-azionabilità dei pacta nel diritto civile, eccetto quelli che rientravano nel sistema dei contratti nominati oppure innominati reali, è rimasta un dogma tra glossatori e commentatori, incontestabile anche per i canonisti. Tale dogma è basato sulla lettura del D. 2,14,7,4. Esso non ha però impedito ai giuristi medievali di elaborare la teoria dell'obbligatorietà dei pacta non-azionabili iure civili (i.e. pacta nuda, v. infra), nell'ambito del ius naturale. Quanto sia dovuto in questa materia alla lettura stessa dei testi del Digesto, e quanto invece all'influsso della teologia, è discutibile 22 .

Nel Digesto non mancano certo i punti di aggancio per l'idea della forza vincolante dei pacta nuda iure naturali. Nella glossa De obligationibus alle Istituzioni di Giustiniano (I. 3,13pr. - 1), considerando la questione se le obbligazioni così dette naturali rientrano nella definizione dell'obbligazione che apre il rispettivo titolo del manuale, Accursio richiama il D. 46,1,16,3-4 $4^{23}$ come l'argomento in favore della risposta affermativa. Il testo dice infatti che la garanzia personale in forma di fideiussio data per il debito naturale è valida e che non si può

21 Azo, Summa Aurea, Lugdunum 1537, C. 2,1 (n.3).

22 J. Gordey, The Philosophical Origins of Modern Contact Doctrine, Oxford 1991, p.41, sostiene che i glossatori arrivano al riconoscimento dell'obbligatorietà dei pacta nuda iure naturali esclusivamente in base alla lettura del Digesto. K.P. NANZ, op. cit., p. 42 (n. 103), osserva però giustamente che l'idea che il pactum nudum genera l'obbligazione naturale non si trova nei testi dei giuristi romani, bensì è dovuta al pensiero degli stessi giuristi medievali.

23 D. 46,1,16,3-4 Iulianus, 53 dig.,: Fideiussor accipi potest, quotiens est aliqua obligatio civilis vel naturalis, cui applicetur. (4) Naturales obligationes non eo solo aestimantur, si actio aliqua eorum nomine competit, verum etiam cum soluta pecunia repeti non potest: nam licet minus proprie debere dicantur naturales debitores, per abusionem intellegi possunt debitores et, qui ab his pecuniam recipiunt, debitum sibi recepisse. 
ripetere la restituzione di ciò che è stato volontariamente prestato. Ciò presuppone l'esistenza di un vinculum iuris tra il creditore e il debitore, e quindi anche dell'obbligazione, secondo la definizione data all'apertura del titolo ${ }^{24}$ - conclude Accursio. In seguito il glossatore spiega che, chi è vincolato dall'obbligazione naturale è obbligato secondo il ius gentium, perché a tutti gli uomini conviene rispettare tali obbligazioni: ubicumque autem dico quod naturali obligatione quis tenetur, intelligo de iure gentium, quia convenit solis hominibus et omnibus ${ }^{25}$. Inoltre, nella glossa Secundum allo stesso frammento egli precisa che i 'diritti della nostra civitas', in virtù dei quali possiamo essere vincolati alla prestazione secondo la definizione giustinianea, comprendono sia il diritto civile che quello naturale: cum obligatio sic definitur, secundum iura romana, sic civilis et naturalis est simul definitum ${ }^{26}$.

Anche se i testi giustinianei indubbiamente lasciano intravvedere una certa rilevanza dei pacta non-azionabili ai fini del ius civile ${ }^{27}$, nel discorso accursiano vi sono degli elementi che vanno oltre le conclusioni raggiunte dai giuristi romani. Si tratta, da un lato dell'idea dell'obbligo positivo (anche se non tutelato da nessun mezzo di coercizione), di effettuare la prestazione accordata, anche se non azionabile nel diritto civile ${ }^{28}$,

24 I. 3,13 pr: obligatio est iuris vinculum, quo necessitate adstringimur alicuius solvendae rei secundum nostrae civitatis iura.

25 I. 3,13 pr., glossa Nunc transeamus. Nel passo citato Accursio si riferisce alla distinzione ulpianea tra il ius naturale e il ius gentium: il secondo più limitato del primo, in quanto si riferisce ai soli uomini, mentre il diritto naturale comprende anche gli animali.

26 Accursius (I. 3,13 pr., glossa Secundum) aggiunge che quanto detto si riferisce a tutta la definizione. Egli distingue inoltre tre configurazioni possibili, ossia la situazione in cui un'obbligazione è vincolante sia iure civili che iure naturali, quella in cui essa è vincolante solo iure naturali, e infine quella in cui un'obbligazione, benché vincolante iure civili, non è tale iure naturali. Con quest'ultima egli probabilmente intende un'obbligazione civile, l'esecuzione della quale può essere bloccata con una exceptio, cfr. glossa Necessitate.

27 Cfr. H. Dilcher, op. cit, p. 273

28 H. Dilcher, op. cit, p. 280-281 punta su fatto che Accursio, nella glossa saepe al C.8,37(38),5, riconosce la possibilità della litis contestatio in base al pactum nudum, confermato da una stipulatio poene, in alternativa all'actio ex stipulato. Accursio segue qui l'idea di Giovanni Bassiano. 
e dall'altro dell'insistenza sul consenso, in quanto ragione principale - e secondo il diritto naturale perfino sufficiente - dell'obbligazione ${ }^{29}$. Tant'è vero che il dogma della non azionabilità dei pacta nuda rimane intatto per Accursio ${ }^{30}$, così come lo rimarrà anche per i commentatori.

Il riconoscimento che il pactum, benché non azionabile iure civili, sia vincolante secondo il ius naturale, per i glossatori e commentatori sembra talmente evidente che non si spingono a dimostrare le ragioni di tale effetto. Inoltre, tenendo ferma la regola della loro non-azionabilità nel diritto civile, non si interessano nemmeno degli eventuali limiti della loro obbligatorietà iure naturali. Quest'ultimo compito verrà ripreso dai teologi morali del cinquecento (v. infra).

Partendo dal presupposto che la sostanza del contratto consiste nel consenso, i glossatori (e successivamente i commentatori) affrontano il problema della distinzione tra i contratti azionabili e quelli privi di un tale effetto nel diritto civile ${ }^{31}$. Il consenso si rivela nel loro pensiero una condizione sufficiente per far sorgere l'obbligazione naturale, ma non quella civile - necessario a quest'ultimo scopo è un elemento aggiuntivo in base al quale l'ordinamento giuridico positivo (ius civile) concede al contratto una tutela giuridica.

Contrapposta alla classe dei contratti che non generano l'obbligazione civile, i.e. pacta nuda, è la categoria dei contratti azionabili secondo il ius civile: questi vengono collettivamente denominati pacta vestita, per contrapposizione ai pacta nuda ${ }^{32}$. L'elemento aggiuntivo al consenso che

29 K.P. NANZ, op. cit., p. 42 (n. 103).

30 Nella glossa Necessitate ad I. 3,13pr. Accursio spiega che l'adempimento dell'obbligazione naturale non si può esigere, benché non si debba restituire la soluzione volontariamente prestata: Hec naturalis vim non habet exigendi, impenditur soluti repetitionem. In seguito egli dice che qualche elemento aggiunto al consenso e proveniente dal ius civile, ossia il vestito, è necessario affinché un'obbligazione naturale diventasse azionabile: Huic quandocumque accedit civilis radix quae illi naturali faciem dat vel formam vel vestem, ut possit parere actionem.

31 Cfr. K.P. NAnz, op. cit., p. 41: „Man ging aus von dem Charakter des pactum als Konsens der Parteien: pactum est duorum vel plurium in idem placitus consensus“. Da dieser Konsens unabdingbarer Bestandteil sämtlicher Verträge war, musste angegeben werden, worin der Unterschied von pactum nudum und den pacta vestita lag“.

32 A. Söllner, op. cit. p. 217. 
li rende azionabili, viene denominato conseguentemente, vestimentum pacti $^{33}$. I singoli tipi di vestimenta corrispondono ai singoli tipi di contratto azionabili nel diritto romano ${ }^{34}$. Azzone ne individua sei, di cui quattro corrispondono esattamente ai quattro tipi di contratti riportati nelle Istituzioni di Giustiniano (I. 3,13,2): re, verbis, consensu, litteris, a cui vengono aggiunti due vestimenta ulteriori, corrispondenti ai pacta adiecta: contractus cohaerentia e ai contratti innominati: rei interventus ${ }^{35}$. Nel pensiero di Azzone un vestimentum, che può appartenere al pactum sin dal momento della sua conclusione (come avviene con i primi quattro vestimenta), oppure essere aggiunto ex post (nei ultimi due), fa parte della caratteristica del pactum stesso, e dunque si distingue dall'azione che ne è un effetto. Ragione, questa, per cui Azzone classifica pacta legitima (azionabili in virtù della legge o dell'editto pretorio), coma pacta nuda che solo eccezionalmente, per via di un miracolo come egli osserva, danno luogo all'azione civile ${ }^{36}$. Nella visione di Azzone infatti pactum

33 Nel Piacentino ancora il pactum indutum (Summa Codicis, C. 2,3), da Azzone in poi il pactum vestitum (cfr. K.P. NANZ, op. cit., p. 32-33).

34 Così già Piacentino (ibidem), cfr. H. Dilcher, op.cit., p. 277. I civilisti francesi, c.d. Ultramontani, hanno riconosciuto soltanto un vestimentum, cioè rei interventus, classificando i contratti nominati del diritto romano come pacta nuda. Per la loro dottrina v. R. Volante, op. cit., pp. 341-405.

35 Azo, Summa Aurea, C. 2,3, n.14: Et si quidem pactum fuerit nudum propter nimiam frigiditatem parere actionem non potest: nisi mirabiliter hoc in quibusdam casibus accidat, in quibus casibus nudum pactum parit actionem in donatione. Item in constituta pecunia (...). Si autem non fuerit nudum, sed vestitum, actionem parit. Sic enim ei nomen recte impono: quia si aliquod est nudum: ex eo quod actio non datur: ergo aliquod est vestitum quia actionem indulget. N. 15: vestitur autem pactum VI modis: re, verbis, consensu, literis, contractus coherentia, rei interventu, ut Institut. De obliga., qui imo potest etiam addi et septimus modus quodam mirabili intellectu, scilicet rei principio (polit). N. 16: Et est notandum quod pactum quattuor primis modis dicitur vestitum sic ut nullo tempore fuerit sine illis vestimentis: hec vestimenta cum suo esse incipit habere. Ultimus vero duobis modis vestitur post nativitatem: cfr. K.P. NANZ, op. cit., p. 33 ; R. Volante, op. cit., p. 133-137. Volante vede gli ultimi due tipi dei pacta, quali cohaerentia contractus e rei innerventus come un contributo particolarmente importante di Azzone alla sistematizzazione dei pacta, il quale ha dato spunto allo sviluppo successivo dell'intera categoria (op. cit., p. 135).

36 H. Dilcher, op. cit., pp. 278-279, sottolinea l'importanza del fatto che Azzone ha lasciato pacta praetoria e pacta legitima fuori della categoria dei pacta vestita, così 
nudum è per sua propria natura incapace di 'produrre' un'azione, in quanto troppo debole, ossia, per usare le sue parole, frigido: propter nimiam frigiditatem parere actionem non potest. In questo modo di pensare si rivela una certa substantiatio dei pacta che hanno una propria natura che rimane immutata nonostante un intervento legale (l'idea, questa, che verrà ripresa e sviluppata da Bartolo). E' la stessa natura che fa nascere da un patto, anche se nudo, l'obbligazione naturale ${ }^{37}$. Diversamente, per Accursio, la concessione dell'actio per via della legge diventa un settimo vestimentum, denominato auxilium legis ${ }^{38}$.

L'elaborazione più articolata della dottrina dei vestimenta pactorum è quella di Bartolo ${ }^{39}$. Nel Commentario al titolo de pactis del Digesto egli propone la summa divisio di tutti i vestimenti, tra quelli provenienti dal ius gentium, e quelli dovuti al ius civile. Nella prima categoria rientrano il nomen, il rei interventus e la cohaerentia contractus. Con il nome sono vestiti sia contratti consensuali che quelli reali della sistemazione gaiana. Rei interventus invece, detto anche implementum iustae causae (con riferimento al D. 2,14,7,2, v. supra), è il vestimentum dei contratti reali innominati. Cohaerentia contractus si riferisce ai patti aggiunti ai contratti iuris gentium. La classe dei vestimenta provenienti dal ius civile è invece composta da: nomen et forma (perché il diritto civile, a differenza del ius gentium, non può vestire il patto solo con il nomen, senza dargli contemporaneamente anche una forma ${ }^{40}$ ), cohaerentia

creando il concetto nuovo dell'azionabile pactum nudum. Di conseguenza, nella sua visione il pactum nudum non è più quello non-azionabile (come lo era per i giuristi romani), ma piuttosto quello non vestito. Tale impostazione è basata sul riconoscimento implicito che il tratto distintivo del contratto sia il vestimentum, piuttosto che l'azionabilità.

37 Azo, Summa Aurea, C. 2,3, n. 2: Nam etiam nudum pactum hoc habet: ut naturalem obligationem inducat.

38 Cfr. H. Dilcher, op. cit., pp. 279-280; K.P. NAnz, op. cit., p. 33; A. Söllner, op. cit., p. 218; R. Volante, op. cit., p. 161.

39 Cfr. H. Dilcher, op. cit., pp. 293-294.

40 Bartolus de Saxoferrato, Commentaria in primam digesti veteris partem, Lugdunum 1538, D. 2,14,7,5, (n.16): Quando nomen imponitur contractui a iure gentium, tunc noment est elegans vestimentum: quando imponitur noment contractui a iure civili, 
contractus, iusiurandum et operis initio ${ }^{41}$. Bartolo inoltre, seguendo la scia di Azzone, distingue puntualmente tra il vestimentum e l'azionabilità del pactum, sostenendo che i vestimenta non sono idonei a produrre l'azione di per se, ma hanno bisogno dell'intervento ulteriore da parte del ius civile a tale scopo (così come un uomo e una donna hanno bisogno di un ausilio dei pianeti, affinché possano generare figli, chiarisce Bartolo): vestimenta non sunt sufficientia ad producendam actionem, nisi cum iuris civilis auxilio. Sicut enim dicitur, homo hominem generari et sol: hoc est cum auxilio solis. Non enim masculus et femina per se essent sufficientes ad generandum, nisi cum auxilio planetarum $)^{42}$. Questo ausilio ulteriore da parte del ius civile, consistente nella concessione di un'actio, è una causa agens ${ }^{43}$ che rende il patto produttivo di un'obbligazione civile ${ }^{44}$. L'auxilio legis - continua Bartolo - è talmente potente che può rendere

tunc nomen non est elegans vestimentum, nisi ei detur nomen et forma, puta cum in eo requiratur scriptura.

41 Bartolus, Commentaria, D. 2,14,7,5, (n.14 - 16): Dico ergo quod pactum vestitur quandocumque ex iure gentium, quandocumque ex iure civili. Iure gentium tribus modis: primo vestitur nomine: hoc comprehendit contractus qui celebrantur re vel consensu, ideo enim dicuntur vestiti quod a iure gentium sibi nomen est additum. Secundum vestimentum est rei interventus, seu implementum iustae causae, tertium vestimentum est cohaerentia contractus. 16) De iure vero civili pacta vestiuntur nomine et forma, ut in contractibus inductis a iure civili. Item cohaerentia contractus. Item iureiurandum. Item operis initio.

42 Bartolus, Commentaria, D. 2,14,7,5 (n.16).

43 La nozione di causa agens, detta anche efficiens, rinvia alla dottrina aristotelica di quattro causae, la quale ha giunto i giuristi medioevali attraverso lo studio di Artes Liberales, cfr. A. Söllner, op. cit., p. 187. La causa agens è una delle due cause estrinseche (accanto alla causa finalis), ossia tali che non risiedono nella cosa stessa, ma agiscono su di essa dal di fuori, provocandone un movimento o una trasformazione. (A. Söllner, op. cit. p. 185). Una causa efficiens è necessaria affinché una materia realizzi la sua potenzialità: così il pactum vestitum raggiunge la sua potenzialità di essere vincolante grazie ad intervento della legge che ne fornisce una tutela giuridica. Nell'impostazione di Bartolo solo i pacta vestita hanno una potenzialità del genere. Pacta nuda possono anche diventare vincolanti grazie all'intervento della legge, ma ciò avviene quasi contro la loro natura, ossia per miracolo, cioè nonostante gli manca tale potenzialità.

44 Bartolus, Commentaria, D. 2,14,7,5 (n.16): Et ideo concludo quod illi qui dicunt vestiri pactum legis auxilio non bene loquuntur. Non enim legis auxilium est vestimentum: 
azionabile perfino un pactum nudum, anche se non in via generale, ma solo in alcuni casi eccezionali. Anche qui egli ricorre ad una efficace analogia, questa volta con i casi di Maria e di Elisabetta raccontati nel Vangelo secondo Luca: la prima vergine, la seconda sterile, hanno sì partorito dei figli, e ciò grazie ad un miracolo: concedo quod miraculosae posset sterilis parere vel virgo, ut habemus Luc. Maria et Elisabetha. Ita lex casualiter et miracolosae facit quod pactum nudum, remanens nudum, producit actiones aliquo favore, vel lex producit propter pactum ${ }^{45}$. Nello stesso modo, grazie all'intervento di una lex, un patto, pur rimanendo nudo, può miracolosamente generare un'azione. Così Bartolo ritorna all'idea di Azzone, togliendo l'auxilio legis dal novero dei vestimenta pactorum e riconducendo i pacta legitima alla categoria di pacta nuda, fatti azionabili soltanto in via eccezionale ${ }^{46}$.

Un altro problema importante affrontato da Bartolo è quello del vestimentum dei contratti consensuali. Una certa tensione tra il dogma della non-azionabilità del nudum pactum (equivalente del nudum consensum nel pensiero medioevale), e l'idea che il consensus possa essere un vestimentum pacti (come lo sarebbe, sin da Azzone e fino a Accursio, presso i quattro contratti consensuali del diritto romano, cfr. supra), è già stata notata dagli stessi glossatori ${ }^{47}$. Nella glossa Quinnimo ad D. 2,14,7,5 Accursio aveva infatti osservato che, una volta riconosciuto che il consensus sia un vestimentum, tutti i pacta dovrebbero ritenersi vestiti (e quindi idonei a generare l'obbligazione civile) ${ }^{48}$. Rispondendo che il consensus è un vestimentum troppo debole

sed est quaedam causa agens in ipso pacto vestito. Est tamen tantae potentiae quod si vult faceret ipsum pactum nudum parere actionem, non regulariter, sed casualiter.

45 Bartolus, Commentaria, D. 2,14,7,5 (n.17-18).

46 Il concetto accursiano dell'auxilium legis come uno dei vestimenta pactorum non è stato infatti accolto dai suoi successori. Già Odofredus torna all'idea di Azzone, eliminando l'auxilium legis dal novero dei vestimenta. Cfr., H. Dilcher, op. cit., p. 280.

47 K.P. NANZ, op. cit., p. 41: „Ein solcher Begründigsversuch führte zu neuen Problemen, denn auf diese Weise war nicht erklärt, warum der Konsens bei den Konsensualkontrakten eine Klage erzeugte, beim pactum nudum dagegen nicht.“

48 Nella glossa Igitur ad D. 2,14,7,4 Accursio nota, che pure la vendita potrebbe considerarsi un pactum nudum, in quanto non ha nessun altro vestimento oltre il consenso: sic et dici potest venditio nudum pactum, ab aliis vestimentis praeter consensum. Come 
per generare l'obbligazione civile, tranne in alcuni casi eccezionali, egli ha risolto il problema: Elegans et tenius vestis est consensus, quae non datur nisi certis contractibus enumeratis, qui cum sint favorabiles et pingues et calidi, levi veste vestiuntur ${ }^{49}$.

Bartolo si allaccia alla risposta di Accursio ${ }^{50}$, confermandola con un'analogia, facendo riferimento, questa volta, ad un uomo giovane, al quale basta un vestimento leggero per sentirsi al suo aggio, a differenza di quello vecchio e debole, che sente freddo anche se vestito con molti vestiti. I contratti consensuali sarebbero dunque come quei giovanotti, a cui basta un vestimento leggero, e quindi il solo consensus ${ }^{51}$.

In definitiva però Bartolo respinge l'idea che il consensus sia uno dei vestimenta pactorum ${ }^{52}$. Conseguentemente, i quattro contratti consensuali del diritto romano nella sua visione sono vestiti non più con il consenso, bensì con il nomen ottenuto dal ius gentium (così come lo sono anche i contratti reali). Il nomen è un segno della loro struttura tipica che hanno ricevuto dal ius gentium. Lo si evince dal paragone con i contratti reali, anche questi nati nell'ambito del ius gentium e vestiti solo con i nomina: i loro nomina però, a differenza di quelli dei contratti consensuali, rinviano alla datio rei come momento che genera l'obbligazione ${ }^{53}$. Dalla trattazione di Bartolo traspare dunque

giustamente osserva A. Söllner, op. cit., pp. 218-219, dall'osservazione di Accursio si evince che i 4 contratti consensuali del diritto romano a rigore non si lasciano ricondurre alla categoria di pacta vestita.

49 Accursius, Glossa Quinnimo ad D. 2,14,7,5.

50 Bartolus, Commentaria, D. 2,14,7,5 (n.16): Respondit Glossa, Institu. de obliga. quae ex consensu: consensus non est sufficiens vestimentum, nisi in quibusdam contractis enumeratis, illi enim casus sunt favorabiliores (...) sic levi veste vestiuntur.

51 Bartolus, Commentaria, D. 2,14,7,5 (n.16): Exemplum uni iuveni recenti et callido sufficeret unum leve vestimentum, sed uni macilento et debili non sufficerent plura vestimenta ut dicatur inductus sufficienter, et ita dicit glossa.

52 Bartolus, Commentaria, D. 2,14,7,5 (n.16): Sed ut clarius intellegas tu potes sic dicere: pactum seu conventio nuda est, illud quod fiat in puris et nudis finibus conventionis: illud dicitur est vestimentum cui post sui originem vel in sui origine aliquid super adiciit. Illud enim quod superadicitur dicitur vestimentum.

53 Bartolus, Commentaria, D. 2,14,7pr: (n.2). Dices tu, quare olim ex pacto nudo donationis non oriebatur actio, si erat contractus nominatus. Contracti nominati producunt actionem eo ipso, quod sunt et nomen habent: quidam contractus denominatur 
ancora la dottrina dei glossatori, sulla particolare forza dei contratti consensuali, in quanto gli unici ai quali il consenso basta per renderli efficaci iure civili.

Riassumendo: Nella dottrina dei glossatori e commentatori, il pactum è definito come il consenso tra due o più persone e in quanto tale comprende tutte le convenzioni (ossia tutti i contratti), efficaci sia iure civili che soltanto iure naturali, a prescindere dal loro contenuto. Il consenso è indispensabile per ogni contratto (ne costituisce l'essenza) ma non è sufficiente per produrre un'obbligazione civile. A tal fine è necessario un elemento ulteriore aggiunto al consenso, ossia un vestimentum. Solo il pactum vestitum è per sua natura capace di produrre un'obbligazione civile - ha la materia sufficiente a tale scopo -, ragion per cui può essere reso azionabile dal diritto civile. Il diritto civile può anch 'esso rendere azionabile un pactum nudum, senza renderlo vestito, ma soltanto eccezionalmente e quasi per miracolo. Il diritto civile può anche 'vestire' un pactum, come si evince dalla categoria bartoliana dei pacta inducta a iure civili, ma la sua capacità di farlo non è illimitata: lo dimostra l'impossibilità di vestire il pactum nudum con il nomen solo nel diritto civile. In ogni caso, nella concettualizzazione di Bartolo, l'essenza del pactum rimane dunque, fino ad un certo punto, indipendente dal diritto civile. Va notato inoltre, che nessun dei vestimenta consiste nella reciprocità delle prestazioni concordate: il carattere sinallagmatico o meno non è un criterio distintivo nell'ambito dei contratti e non sembra avere particolare rilevanza né per i glossatori né per i commentatori. Lelemento che rileva nell'ambito dei contratti reali innominati, fungendo loro da vestimentum e quindi rendendoli azionabili, non è la reciprocità delle prestazioni, bensì il fatto di averne eseguita una, come viene evidenziato dalla denominazione del rispettivo vestimentum come rei interventus, ossia iustae causae implementum, come precisa Bartolo. Il pactum nudum vice versa - anche questo un dogma ripetuto da tutti i giuristi medievali - produce l'obbligazione naturale. I civilisti non

ex actu paciscendi seu conveniendi, quidam denominant ex actu exequendi. Si loqueris in primis quidam denominantur ab actu paciscendi, statim facto pacto habent nomen et generant actionem. (n.3). Si denominant ab actu exequendi, non habent nomen, nisi facta executione: exemplum in contractibus quae re contrahuntur. 
approfondiscono tuttavia i motivi dell'efficacia dei pacta nuda iure naturali, lasciando questo compito ai canonisti e ai teologi morali.

Se per i civilisti (glossatori e commentatori) il pactum consiste nell'accordo tra due volontà e in quanto tale equivale al contratto nel senso lato, nella riflessione dei canonisti - sviluppata dai teologi morali del cinquecento - questo viene ricondotto al concetto della promessa. Il pactum viene comunemente descritto come una promessa accettat ${ }^{54}$. Dal contractus si distingue per il fatto che genera solo un'obbligazione (del promettente nei confronti del promissario), mentre il contractus nel senso stretto, conformemente alla definizione labeoniana (richiamata dai teologi morali), crea le obbligazioni reciproche ${ }^{55}$. Nell'impostazione di De Molina il termine pactum comprende anche i contratti in senso stretto, essendo il termine più ampio del contractus, invece, in quella del Lessius equivale al contratto nel senso lato ${ }^{56}$. I contratti sinallagmatici consistono in promesse reciproche, accettate a vicenda da ciascuno

54 L. De Molina, De iustita et iure, Tom. II (Disputationes de contractibus), Venetiae 1607, Tract. 2, Disp. 252.2: Pactum est duorum consensus atque conventio. Hinc constat pollicitationem seu promissionem, interim dum acceptatat non est, pactum non est: eo quod non sit duorum in idem placitum et conventio, sed sit solum offerentis promissum. (...) Quod autem acceptata iam est, tunc vere orritur rationem pactis, ut. Pan. In C.1. de pactis num. 4 recte cum Bartolum affirmat”. L. Lessius, De Iustitia et iure, Lib. II, sec. III, Cap. 17, Dub.1, 5: "Ut enim fiat pactum, necesse est, ut duae voluntates in idem conveniant reciproco consensu. Dico reciproco consensu, quia non sufficit ut quovis modo in idem conveniant, sed requiritur ut consensus suos in se mutuo dirigant. Unde donatio et promissio, etsi a duobus communi consensu fiant, antequam sint acceptate et accedat consensus reciprocus eius in quem dirigitur, non habent rationem pacti: sed per acceptionem transeunt in pactum.

55 L. De Molina, op. cit., Disp. 252.3: contractum est pactum ex quo ultro citroque oritur obligatio. L. Lessius, De Iustitia et iure, Lib. II, sec. III, Cap. 17, Dub. 1, 2: Itaque contractus est signum externum practicum, ultro citroque obligationem ex consensu contrahentium pariens". Insiste su questa distinzione I. BIRocchi, Causa e categoria generale del contratto, Torino 1977, p. 225. L'importanza di quella distinzione viene però diminuita dagli stessi teologi morali, come si evince dai testi, citati in seguito (n. 56).

56 L. Lessius, De Iustitia et iure libri VI, Lugdunum 1653, Lib. II, Sec. III, Cap. 17, Dub. 1, 4: Sic Contractus est conventio duorum, obligationem saltem in alterutro pariens. Quo modo non distinguitur a pacto, quod definitur esse duorum consensus atque conventio. 
dei contraenti. Di conseguenza, una volta deciso che il patto, inteso come una promessa unilaterale accettata, sia vincolante, ne consegue che vincolanti sono anche i contratti sinallagmatici. Nell'ambito di quest'ultimi ciascuna delle promesse è condizionata, ossia dipende dalla promessa reciproca ${ }^{57}$. Per ciascuno dei contraenti la prestazione spettante dall'altro è la causa della propria promessa ${ }^{58}$ : le promesse reciproche vengono dunque fatte ex causa lucrativa nell'ambito dei contratti sinallagmatici, a differenza delle promesse unilaterali, fatte ex causa liberale.

Tutta la riflessione dei teologi morali sulla forza vincolante dei pactae quindi anche dei contratti in generale - si concentra sulla sola volontà del promittente. L'elemento vincolante del pactum secondo il diritto naturale si rivela esclusivamente la volontà del promittente di obbligarsi ad una determinata prestazione futura (quella cioè che costituisce l'oggetto della promessa). Emblematica per questa concezione è la descrizione fornita da De Molina, il quale riconduce i verbi e la scrittura ai soli segni esteriori della volontà interna del promittente, incapaci di generare una qualsiasi obbligazione di per se, ossia in mancanza della decisione interna di costui di vincolarsi: voces et scripta sunt signa conceptuum, neque vim habent obligandi, nisi ex interiori actu, quem exprimunt, atque ex voluntatis intentione se obligandi (Disp. 266, 5). De Molina porta questo modo di pensare alle sue estreme conseguenze, in quanto ritiene che le promesse siano vincolanti iure naturali non solo già prima di essere accettate dal promissario, ma perfino quelle non espresse,

57 L. De Molina, op. cit., Disp. 262.16: Est enim magnopere advertendum discrimen, quod Sotus loco citato et alibi inter gratuitam promissionem et non gratuitam seu respectivam, qualis in contractibus cernitur, tradit. Quod respectiva promissio pretii in emptione, et ducendi uxorem in sponsalibus, etiam ad obligandum exparte promittentis, est sua propter natura condicionalis, si et tu restituas ac repromittas, eaque causa, ante utriusque promissionem completant, neutra obligat, sed fas est cuicumque libere ab ea discedere.

58 D. De Soto, 'De Iustitia et iure libri X', Lugdunum 1559, Lib. VI, Quaest. I, Art. 1: Contractus est ultro citroquae obligatio quod Graeci synallagma vocant: hoc est consecutum, quando videlicet quippiam ego causa tui, tu causa mei, accepta dataquae utrinque fide conficimus. (...). Quia stato pretio paciscimur, me tibi merces traditum, te vero mihi idem pretium, mutua emerget ex venditione obligatio. 
ossia meramente interne (ergo donatio aut promissio mere interna, vim habet obligandi in foro conscientiae, non solo si Deo fiat, sed etiam si fiat homini, Disp. 266, 5), a patto che fossero serie, i.e. confermate dal giuramento interno. De Molina arriva a sostenere che il promissario ottiene il diritto all'oggetto di una tale promessa interna, il quale passa ai suoi eredi ${ }^{59}$. Il teologo spagnolo riconosce una scarsa rilevanza pratica della teoria in questione, ma sottolinea che la sua presa di posizione è la conseguenza logica del riconoscimento che la volontà del promittente sia un elemento necessario e al contempo sufficiente per la forza vincolante della promessa (Disp. 266, 2). Va da se che si tratta della forza vincolane in foro conscientiae, non estendibile agli ordinamenti giuridici positivi. Notevole è il fatto che altri teologi morali, quali De Soto ${ }^{60}$ e Lessius $^{61}$, pur non accettando la tesi radicale, come quella di De Molina, la ritengono probabile, proprio perché partono anche loro dal presupposto del carattere vincolante del mero atto di volontà del promittente. Nella prassi confessoria l'idea che l'inadempimento di una siffatta promessa

59 L. De Molina, op. cit., Disp. 266, 7: Postremo, promissio interior de re non illicita homini facta, si iuramento, etiam mere interno, confirmetur, sub lethali culpa obbligat ad implementum eius, quod promissum est, idque non solum conparatione Dei, sed et comparatione homini, cur talis promissio est facta isque comparat verum ius ad istam rem, estque sibi vere debita, iusque illud transfert ad ipsius heredes.

60 D. De Soto, op. cit, Lib. VII, Quaest. II, Art. 1: At probabilius forte est eam quae sola mente fit, non obligare.

61 L. Lessius, op. cit, Lib. II, Sec. III, Caput 18, Dub. 5 (28-30): Etsi promissio vel donatio, pure interna, facta Deo, obliget nos Deo, non tamen facta homini obligat nos homini. 29. Est communis sententia D.D. Sed difficultas est, utrum id proveniat ex solo iure positivo, an ex iure naturali. Quidam putant id provenire ex solo iure positivo, consistendo enim intra limites iuris naturalis talem actum inducere veram obligationem. Ita Ledesma in 4.p.2q.18.2.1.dub. 13 et inclinat Sotus, lib. 7 q.1.art.2, Molina Disp. 266. (...). Tertio: tota vis obbligandi promissionis et donationis est a voluntate interna: ergo haec sufficiens est ad obligandum. Confirmatur, quia expressio exterior non est necessaria, nisi ut posse cognosci et acceptari ab altero, atqui haec acceptatio iure nature non est necessaria. Haec sententia est probabilis. 30. Dico secundo, Probabilius tamen videtur, promissionem donationemque internam iure naturae esse insufficientem ed invalidam ad obligandum. Colligitur ex D. Thoma quaet. 88 art. 1 ubi dicit, promissionem unius homini non posse alteri fieri, nisi per signa externa, Deo autem posse fieri per internam cogitationem. 
sia un peccato, e cioè mortale, poteva creare una sorta di pressione almeno su alcuni penitenti.

Più pratica era la questione della forza vincolante della promessa esteriorizzata, ma non ancora accettata, ossia prima che il promissario ne avesse preso atto. Il problema poteva sorgere nel caso delle promesse spedite al promissario tramite messaggero. Partendo dal presupposto del carattere decisivo dall'atto della volizione del promittente per la forza obbligatoria della promessa, non era affatto facile escludere che essa fosse vincolante già prima dell'accettazione. La maggioranza dei teologi ha risolto il problema, interpretando la promessa come condizionata, i.e. dipendente dall'accettazione da parte del promissario, ragion per cui diventava vincolante solo in quest'ultimo momento. Dibattuta fu la questione se tale condizione esistesse già nel diritto naturale, ossia in foro coscientiae, come sostenne De Ledesma, oppure fosse stata imposta soltanto dal diritto positivo, secondo l'opinione di De Molina ${ }^{62}$. Quest'ultima opinione aveva il vantaggio di spiegare le eccezioni introdotte dal diritto positivo rispetto alle promesse ex pie cause, ritenute valide indipendentemente dall'accettazione ${ }^{63}$, e quindi irrevocabili. Se la validità delle promesse dipendesse dall'accettazione già secondo il diritto naturale, il diritto positivo non avrebbe potuto renderle valide a prescindere da questa - ragionava De Molina. Quanto al diritto naturale dunque la promessa era vincolante anche prima dell'accettazione, veniva però sciolta se il promissario, avendone preso atto, avesse rifiutato di accettarla ${ }^{64}$.

L'impostazione, secondo cui la forza vincolante del pactum dipende interamente dalla volontà del promittente di obbligarsi, porta ad un'altra conseguenza importante, cioè la negazione dell'esistenza dell'obbligazione, almeno in foro coscienze, qualora tale intenzione

62 Cfr. L. Lessius, loc. cit. sup.

63 L. De Molina, op. cit., Disp. 262.15: Sicut autem ius positivum acceptationem donatarii introduxit, tamquam condicionem, sine qua non obligaret, ita in aliquibus potuit illam omnino remittere, ut in promissionibus civitati factis.

64 L. De Molina, op. cit., Disp. 262.16: Semper quidem promissio eatenus ex acceptatione donatarii ex natura rei pendet, quatenus, si ille non acceptet, obbligatio, quae ex illarum natura oriebatur, dossolvetur. 
mancasse. Tale convinzione ha aperto la strada per lo sviluppo della teoria dei vizi della volontà ${ }^{65}$.

Mentre i teologi morali della seconda scolastica hanno pienamente condiviso la convinzione dei civilisti e canonisti che ogni promessa accettata (anche quella con la prestazione unilaterale, ossia il pactum nel senso stretto) obbligava il promettente iure naturali, ossia in foro conscientiae, dibattuto era invece il carattere del dovere che ne discendeva. La controversia riguardava la questione, se il promettente fosse obbligato in base alla giustizia, e quindi sotto il peccato mortale, oppure soltanto in base all'onestà morale, i.e. sotto il peccato veniale. Sullo sfondo del dibattito si poneva la distinzione di Tomaso d'Aquino, tra il debito morale, l'adempimento del quale poteva essere lasciato all'onestà morale del debitore, e quello legale, il cui adempimento era necessario, e dunque poteva essere forzato ${ }^{66}$. Soltanto l'ultima opzione, ossia la decisione che si trattava del debito legale, poteva creare la basi sufficiente per rivendicare la sua eseguibilità anche negli ordinamenti del diritto positivo.

Tre opinioni ben distinte si sono cristallizzate nel corso della discussione.

La prima fu quella, sostenuta da Gaetano, secondo cui l'obbligo di adempiere le promesse semplici (i.e. unilaterali, non confermati da nessuna solennità), equivale all'obbligo di dire la verità, e quindi dipende dalla medesima virtù, i.e. dalla onestà. L'inadempimento della promessa costituisce dunque lo stesso peccato della mendacia, e quindi è di propria natura veniale, e non mortale. Urta i principi della giustizia, e quindi diventa mortale, soltanto se il suo oggetto è necessario al promissario, così che non avendolo ricevuto egli subirebbe un danno. In tal caso però l'obbligo di fornire la prestazione è a rigore già esistito a prescindere dalla promessa, e ciò in virtù dei soli precetti della giustizia e della carità nei confronti degli altri. Gaetano riconosce tuttavia come vincolanti in base alla giustizia, e quindi sotto il peccato mortale, le promesse

65 Cfr. W. Deсоск, op. cit., pp. 215-325.

66 Thomas Aquinas, Summa Theologiae, IIa, IIae, Quaestio 80, Art. 1, Concl. Cfr. W. Decock, op. cit., p. 199. 
diventate obbligatori iure civili, argomentando che l'inadempimento di esse annienterebbe il diritto e disturberebbe la vita sociale: Ad secundam autem obiectionem dicitur, quod fides, ut excendit se ad debitum civile, bene obbligat ad mortale: qua eius oppositum tolleret et ius, et socialem vitam (Quaest. 113, Art. 1, p. 623). L'opinione di Gaetano è basata sulla concezione aristotelica della giustizia commutativa, intesa come l'equità nello scambio tra le persone, nell'ambito della quale non rientrano pertanto gli atti della liberalità, e quindi le donazioni e le promesse a titolo oneroso.

Posizione opposta è quella assunta da De Soto, il quale sostiene che tutte le promesse vincolino in base alla giustizia, e quindi sotto il peccato mortale. Egli rifiuta l'opinione di Gaetano ritenendo che la promessa lega il promettente al promissario con il vincolo di fiducia, il quale va oltre il semplice dovere di dire il vero (Non enim est uticunque verum afferere, sed obstringendo alteri fidem, Lib. VII, Quaest. II, Art. 1). Richiamandosi ai de Officiis di Cicerone egli arguisce, che la fides è il fondamento stesso della giustizia, e quindi perfino qualcosa di più dell'ultima, ragion per cui infrangere fides implica la violazione della giustizia. L'obbligo di adempiere alla promessa fa dunque parte, proprio in quanto basato sul vincolo di fiducia, della giustizia commutativa: Enim vero promittere non pertinet simpliciter ad virtutem veritatis, sed reducitur ad commutativam iustitiam. (Lib. VII, Quaest. II, Art. 1). Colui che infrange la fiducia mostratagli da un altro, gli fa un danno, e quindi commette un peccato mortale (Est ergo genere suo peccatum mortale, utpote per quod ingens detrimentum proximo infertur Lib. VII, Quaest. II, Art. 1). De Soto spiega inoltre che, benché fare la promessa fosse un atto della liberalità, l'adempimento di essa è già un atto della giustizia ${ }^{67}$ : la promessa crea infatti un debito nei confronti del promissario, e la restituzione dei debiti è l'ambito proprio della giustizia ${ }^{68}$.

67 D. De Soto, op. cit, Lib. VII, Quaest. II, Art. 1: Nam etsi vouere opus consilii sit, nihilominus reddere est actus iustitiae, quae citra charitatis iniuriam violari non potest: cum sit inter homines maxime necessaria.

68 D. De Soto, op. cit, Lib. VII, Proemium: Absoluta iustitiae ratio tria comprehendit: Primum quod est unius ad alterum. Secundum quod versatur circa debitum: ac tertium 
De Molina condivide l'idea che la promessa crea il dovere nei confronti del promissario, ragion per cui suo adempimento va oltre un semplice atto della liberalità ${ }^{69}$. Egli accetta anche l'opinione che la promessa lega il promettente in base alla fides che è una virtù diversa dall'onestà e attinente alla giustizia. Egli richiama perfino lo stesso passo di Cicerone, ma diversamente da di Soto, insiste sulla distinzione tra fides e giustizia ${ }^{70}$ : la violazione di fides nella sua prospettiva può portare alla violazione della giustizia, ma non la provoca automaticamente ${ }^{71}$. Solo in quel caso l'inadempimento della promessa può essere qualificato come un peccato mortale. In definitiva De Molina propone una soluzione intermedia, distinguendo tra le promesse vincolanti in base alla giustizia, e quelle vincolanti in base all'onestà morale. Partendo dal presupposto che l'effetto vincolante della promessa dipende esclusivamente dall'atto di volontà del promettente, ossia dalla su decisione di vincolarsi, egli conclude che ne dipende anche il carattere el'estensione dell'obbligazione assunta. Se il promettente ha fatto la promessa con l'intenzione di obbligarsi soltanto in base all'onestà, cioè senza concedere il rispettivo diritto al promissario, la violazione di essa costituisce la trasgressione dei

quod aequalitatem soluti et debiti constituit. Liberalitas autem, licet non versatur circa debitum, est nihilominus ad alterum, cui per ipsam beneficium confertur.

69 L. De Molina, op. cit., Disp. 261.12: Confirmatur utraque pars nostrae sententiae, quoniam, cum gratuita promissio ex sola liberalitate promittentis proficiscatur, sane in potestate ipsius est illa solum se obligari ex morali honestate, vel omnino sua sponte debitorem rei promissae se constituere. (...). Sicut enim traditio liberalis titulus est sufficiens ad transferrendum dominum illius: ita promissio liberalis rei alicuius titulus esse potest sufficiens, ut debita fit ex iustitia, si promittens eo usque intendit se obligare.

70 L. De Molina, op. cit., Disp. 261.4: (Cic.1 de off. a fio et dico, quasi per eam fiat quod dictum est $=$ fides). Eandem Tullius ibi definit, esse dictorum conventorumque constantiam et veritatem. Constant quippe, veraque redditur, dicta et conventa, cum fit, quod dictum conventumque est. Subiungit Tullius fidem hanc esse iustitiae fundamentum. Quo loco observa non dixisse, esse iustitiam ipsam, sed iustitiae fundamentum.

71 L. De Molina, op. cit., Disp. 261.5: Obligatio tamen ex fide latius patet, quam obligatio ex iustitia: et quidam iustita ex eo evertitur quod fides non servatur, pacta conventaque non implentur, duo vitia commituntur. Unum iustitiae, ex suo genere lethale, quatenus proximo non redditur quod supposito pacto et conventione, ei ex iustitia debetur. Alterum vero infidelitatis, ex suo genere veniale, ut dicemus, quatenus indecore dictum et conventum opere non impletur, sed falsum efficitur. (...). 
principi di onestà, ma non di quelli della giustizia, e quindi un peccato solamente veniale. Se uno però intende obbligarsi in base alla giustizia, e quindi vuole concedere il diritto al promissario, l'inadempimento della promessa costituisce un peccato mortale ${ }^{72}$. L'adempimento della promessa semplice, può dunque essere forzato dal diritto positivo, a patto che questa fosse stata stretta con l'intenzione di obbligarsi ex iustitia. Tuttavia, l'intenzione di obbligarsi con conseguenze talmente gravi non può essere presunta, dato che è assente nella maggioranza dei promittenti. Pro foro externo quindi, ossia quando si tratta del diritto positivo, l'intenzione di obbligarsi in base alla giustizia deve essere desunta dai segni esteriori, quali: publica scriptura, chirographum subscriptum, adstringendo se id soluturum (262.12).

I teologi morali del cinquecento sono fra i primi a postulare l'adeguamento degli ordinamenti giuridici positivi al diritto naturale, con l'argomento principale che lo scopo ultimo del diritto positivo coincide con quello del diritto naturale, consistendo nel portare la gente alla salvezza. Così Fortunio Garcia (1494 - 1534; coetaneo del De Soto) sostiene che le promesse dovrebbero essere azionabili anche nel diritto civile, proprio perché il mancato adempimento della promessa costituisce un peccato ${ }^{73}$. Giustificando questo parere Garcia dichiara che il diritto civile si sarebbe dovuto conformare al diritto naturale, essendo subordinato a quest'ultimo, e parimenti al diritto canonico ${ }^{74}$. L'ultimo scopo di entrambi i diritti, sia di quello canonico che del civile, secondo il suo parere sarebbe dovuto essere quello di correggere i peccati ${ }^{75}$. De Molina incita i legislatori di seguire l'esempio del Re di Castiglia e di introdurre i mezzi di protezione dei nuda pacta anche nel diritto civile ${ }^{76}$. Egli si spinge perfino a chiedere l'intervento del Papa, che a suo avviso dovrebbe abrogare queste parti del diritto civile

72 L. De Molina, op. cit., Disp. 261.12, cit. sup. (n. 60).

73 W. DeCOCK, op. cit., p. 114.

74 W. Decock, op. cit., p.159.

75 Trattato Repetito super cap. 1 de Pactis 1514, cfr. W. Decock, op. cit., pp. 159-160.

76 L. De Molina, op. cit, Disp. 258, co. 25: ut in Regno Castellae l. illa 3 citta, aut omnino aut magna ex parte, consentanee ad ius canonicum factum est, exteriusquae forum conscientiae forum aequari deberet. Cfr. W. Decock, p. 142. 
che erano contrari al diritto canonico e portavano al peccato ${ }^{77}$. Pedro de Oñiate loda l'armonizzazione del diritto civile con quello naturale e canonico in Spagna, puntando sul fatto che la protezione giuridica del nudo consenso è conforme alla libertà dei contraenti, in quanto fa valere le loro decisioni: "quandocumque de rebus suis voluerint contrahere et se obligare id ratum sit in utroque foro in quo convenerint"78.

Si può dunque concludere che la teologia morale del cinquecento ha aperto la strada alla libertà contrattuale, postulando la tutela giuridica di tutti i contratti fatti ex causa lucrativa (i contratti di scambio), e, sotto determinate condizioni, anche delle promesse unilaterali accettate (pacta sensu stricto), a prescindere dalla loro forma, e cioè in base alla sola volontà dei contraenti di obbligarsi.

Il postulato di estendere l'obbligatorietà dei pacta nuda al diritto positivo non è stato tuttavia accettato unanimemente nel cinquecento. Una prima critica è stata mossa dal discepolo di De Soto, Diego de Covarrubias $^{79}$. Egli ritorna all'idea, largamente condivisa dai civilisti (glossatori e commentatori) e canonisti del secolo precedente, sulla distinzione dei fini, e quindi anche dei contenuti, tra il diritto naturale, canonico e quello civile. La sua polemica parte dalla contestazione della tesi secondo cui nell'ambito dei peccati, perlomeno quelli mortali, il diritto canonico precede quello civile, e quindi, nei casi di contrasto le norme del primo sostituiscono quelle del diritto civile. Covarrubias risponde che tale sostituzione si ha soltanto quando una norma del diritto civile permette, ovvero approva un comportamento, il quale è vietato dal diritto canonico in quanto peccato. Il diritto Romano non approva infatti la violazione dei pacta, anzi, incoraggia il loro adempimento ${ }^{80}$,

77 W. DECOCK, op. cit., p.143.

78 W. Decock, op. cit., p. 164.

79 Sulla posizione di Covarrubias, v. W. DECOCK, op. cit., pp. 114-119.

80 D. Covarrubias y Leyva, Relectio cap. Quamvis pactum, Lugdunum 1558, II, IV, 13: Hunc rationi respondetur verum esse iuri pontificio in utroque foro standum esse, quando tractatur, an aliquid sit permittendum aprobatione quadam, nam si ius canonicum id prohibeat ea ratione, quod peccatum sit, ius civile non poterit it permittere, et si permitterit, iure pontificio cederi debet. At in praesenti tractatu pacti nudi non permittit ius civile approbatione quaedam (...). Covarrubias chiarisce che diritto romano in realtà incoraggia l'adempimento dei pacta nuda, concedendo exceptio, 
ma per ragioni pratiche rifiuta la possibilità di perseguirli con l'azione civile $^{81}$. Inoltre, Covarrubias sottolinea che perfino il diritto canonico non reprime tutti i peccati: la prostituzione per esempio, nonostante fosse un peccato mortale, non è vietata né dal diritto civile, né da quello canonico ${ }^{82}$. Egli continua escludendo l'applicazione del principio dell'applicabilità diretta del diritto canonico nei casi di lacune nel diritto civile: quanto ai pacta nuda il diritto civile non tace affatto, bensì espressamente esclude la possibilità di perseguirli in giudizio, dunque non si può parlare di una lacuna nel diritto ${ }^{83}$. Infine, egli contesta anche la possibilità di 'vestire' il pactum con l'indicazione espressa della causa, analogamente a quanto avviene nel diritto canonico, puntando alla diversa impostazione della causa nel diritto canonico e in quello civile. In quest'ultimo, infatti, soltanto la causa che è stata già adempiuta può vestire un pactum, così come succede nei contratti reali innominati ${ }^{84}$.

nonché la possibilità di compensazione e di ritenzione della prestazione ottenuta. Il rifiuto dell'azione è motivato, nella sua ottica, dalle ragioni dell'utilità pubblica (cfr. infra).

81 D. Covarrubias, op. cit., II, 4, 14: Ius etenim civile, etiam si praetor pacta nuda per exceptionem, retentionem, et compensationem defenderit, ex aequitate iuris naturalis, noluit actionem pactis nudis civilem tribuere, imo eam negavit ad utilitatem reipublicae, ut tot lites quae ratione pactorum simplicium contingere frequentissime possent, foris cederent, et exterminarentur.

82 D. Covarrubias, op. cit., II, 4, 14: Deinde et his accedit, quod fornicatio simplex, atque item ea, quae in publicis lupanaribus exercetur, peccatum est mortale, et tamen nec lex civilis, nec pontificia huic malo medetur, nec eam punire curat.

83 D. Covarrubias, op. cit., II, 4, 14: Secundo adversus comunem Fortuni. in dict. cap.j. num 10 alia utitur ratione, existimans adhuc iure civili post iuris canonici statuta ex pacto nudo actionem dari. Nam si quid omissum sit iure civili, standum est eo iuri pontificio. (...). Sed haec ratio manifeste deficit, quippe quae falsum praemittat, cum hic casus non sit a iure civili omissus, imo expressim decisus.

84 D. Covarrubias, op. cit., II, 4, 14: Iure civili tunc demum pactum alioqui nudo fomentum a causa recipit, cum eius sit effectus sequutus non ex simplici tamen eius appositione. Et sic fometur pactum nudum ab effectu causae: ut si tibi dem pallium, ut eas pro me Romam, ut des mihi equum hoc casu iure civili actio oritur. At si absque exequutione simpliciter adiiciatur causa in hunc modum, dabo tibi centum ut eas pro me Romam: ex hoc pacto iure civili actio non oritur, bene tamen iure pontificio sicuti explicat Fortun. In d.c.j. de pact. Num 34. 
In definitiva, Covarrubias ritorna alla dottrina dei glossatori e commentatori, secondo cui solo i pacta vestita, ossia quelli che oltre al consenso tra le parti hanno un qualche elemento aggiunto, sono azionabili iure civili. Primum pactum nudum id dici, cui praeter consensum et conventionem nihil extrinsecum accedit. Quasi ea pactio, quae in proprium et speciale nomen contracti minime transierit, nec alioquin fomentum extrinsecus acceperit, nuda fit. (...) ${ }^{85}$.

Covarrubias lascia però intatta la dottrina dell'obbligatorietà dei pacta nuda iure naturali. La più forte critica di questo dogma è dovuta ad un civilista francese, François Connan ${ }^{86}$. Il suo modo di argomentare riecheggia infatti quello di Gaetano ${ }^{87}$ : Connan sostiene che adempiere alle promesse è un atto glorioso, però non per questo dovuto in base alla giustizia ${ }^{88}$. Ladempimento della promessa unilaterale produce un vantaggio per il promissario a costo del promittente, ragion per cui non può essere giudicato dovuto in base alla giustizia commutativa, giacché quest'ultima riguarda soltanto i principi dello scambio ${ }^{89}$. Connan però va ben oltre la negazione della forza vincolante dei pacta

85 D. Covarrubias, op. cit., II, IV, 12: His autem solent extrinsecus multa accedere, quae hanc nuditatem tollunt: nempe, verborum solennis forma, i.e. stipulatio, rei traditio, causae expressio: $u$ in donationis aut alicuius rei agendae, aut contractus aliquis praecedens, cui pactum nudum ipsum ex conventu tantum accesserit.

86 L'argomentazione di Connan è basata sul concetto del ius gentium, che nella sua impostazione fa parte del ius naturale, spirata dai principi dell'utilità, e meno stabile del ius naturale nel senso stretto, in quanto fondata sul consenso tra le genti, e quindi passibile degli cambiamenti. Cfr. I. BIROcCHI, Causa e categoria generale del contratto, Torino 1997, pp. 118-119.

87 Cfr. I. Birocchi, op. cit, p. 120.

88 F. Connanus, 'Commentaria iuris civilis tomus I', Parisium 1553, V, 1,1,5: Nunc praestare quod semel pollicitus sis, aut alio quovis modo ostendisti te facturum esse, praeclarum et gloriosum est: sed est tamen gloriosius, quominus necessarium. Nec unquam aliter constitutum fuisse arbitror etiam primo illo iure naturae quod gentium appellamus: quo iure non verborum sed factorum ponderibus aequitas examinabatur. (...) uter nostrum es iniquior, ego qui praestari nolo, quod tibi profuturum est: an tu, qui exigis, quod mihi est nociturum? Nec promissa igitur servanda sunt ea, quae sint iis, quibus promiseris, inutilia: nec si plus tibi noceant, quam illi prosint, cui promiseris.

89 I. BirocCHI, op. cit., pp. 122-123, sottolinea l'ispirazione aristotelica del concetto della giustizia di cui si serve Connan. 
con le promesse unilaterali, escludendo pure l'obbligatorietà, sia iure civili che iure naturali, delle promesse reciproche, ossia dei contratti sinallagmatici, in base al solo consenso. Nella sua prospettiva pure nelle promesse reciproche, ossia nei patti bilaterali, la pretesa nei confronti della controparte nasce solo in seguito all'adempimento della propria prestazione (proprio come avviene nei contratti reali innominati). Solo in tal caso il mancato adempimento può considerarsi a rigore una lesione nei confronti di un altro, e quindi la violazione dei principi della giustizia commutativa $^{90}$. Connan si sforza nel ricondurre a questo schema pure i contratti consensuali nominati del diritto romano ${ }^{91}$. Nell'ambito della vendita la sola fissazione del prezzo avrebbe provocato l'acquisto del diritto da parte del compratore, quasi come se avesse già ricevuto la merce: avremmo dunque a che fare con una specie della traditio ficta, ossia acquisto della res solo consensu. La locazione avrebbe funzionato secondo lo stesso schema. Nella società consensuale i soci avrebbero acquisito solo consensu il possesso delle cose communi, analogamente quanto avvenne nella società omnium bonorum. Connan descrive questo acquisto consensuale del possesso come non parvum simulacrum traditionis. Nel mandato infine, colui che lo accetta assume una sorta di cura degli affari del mandante, quasi come gli fossero 'trasferiti'92.

90 I. BiRocCHI, op. cit., p. 128: "La ragione profonda per cui i contratti ricevevano forza obbligatoria consisteva nel nesso sinallagmatico che veniva a crearsi allorché, in base ad un accordo, si avesse lo spostamento di un certo bene da una parte ad un'altra: perché non si stabilisse una iniqua situazione di perdita dal lato del cedente e di lucro dal lato dell'acquirente sorgeva il dovere di riequilibrare l'assetto del rapporto costituendosi per l'acquirente l'obbligo di procedere ad un analogo spostamento del bene verso il primo cedente". Cfr. F. Connanus, op. cit., V,2,1,326 ab.

91 F. Connanus, op. cit., V,2,1,2: Sic pactum \& conventio perficiscuntur quidem consensu, contractus autem rei traditione aut vera, aut quae iuris auctoritate pro vera habetur.

92 F. Connanus, op. cit., V,2,1,3 : Ecce enim emptio non est, neque vero locatio, quum inter nos convenit, ut fundus meus tibi esset emptus aut locatus, nisi dictum sit et conventum pretium. tum enim aestimatio rei emptionem perficit aut locationem, \& quodammodo pro traditione rei habetur, ut iam hoc solum supersit, pretium ut detur et solvatur suo tempore. Hinc fit, ut res dotalis si detur marito aestimata, pro vendita habeatur, quam in rem lege communi omnium gentium inductus est nummus, ut aestimandibus rebus dominium earum quasi traderet \& transferret. (...) Atq hi soli sunt 
La concezione della giustizia, la quale emerge dalle argomentazioni di Connan, è molto più ristretta rispetto a quella degli scolastici dalla scuola di Salamanca. Il civilista francese, nella stessa scia dei suoi opponenti, parte dalla nozione aristotelica della giustizia commutativa, la limita però rigorosamente ai principi dell'equità nello scambio ${ }^{93}$. Fuori dell'ambito della giustizia rimangono pertanto non solo gli atti a titolo gratuito, ma pure tali nei quali nessun squilibrio patrimoniale non si è ancora creato, come p.e. le promesse reciproche prima di adempiere almeno una delle prestazioni. La teoria di Connan ha avuto non poca risonanza, dato che ancora i rappresentanti del giusnaturalismo settecentesco, Grozio e Pufendorf, si sentono costretti a fare conti con essa ${ }^{94}$.

La teoria groziana dell'obbligatorietà del pactum (che pure nel suo linguaggio, come in quello dei suoi predecessori, è il termine generale per il contratto), si rifà, così come quella dei teologi morali dalla scuola di Salamanca, sul modello della promessa con la prestazione unilaterale ${ }^{95}$. Una volta deciso che tale promessa è vincolante a prescindere dalla sua forma, bisogna ammettere infatti che siano vincolanti a fortiori pure le promesse reciproche, e quindi tutti i contratti informali. Che il debito di Grozio verso la seconda scolastica non sia da sottovalutare, è stato

contractus, qui sine contrectatione rei consensu consummantur ita, ut non liceat alteri invito ab iis discedere. Nam et societas et mandatum, qui item solo consensu dicuntur perfici, habent aliquod, nec illud parvum traditionis simulacrum : Paul. L. pro socio, In societate bonorum omnes res, quae coeuntium sunt, continuo comunicantur, quia licet specialiter traditio non interveniat, tacite tamen creditur intervenire. At et in societate quae non est omnium bonorum, ea de quibus conventum est, pari ratione communicantur : solo autem consensu dicitur consummari : quasi simul ac de eo consensum est, incipit alter alterius res possidere, curamque et diligentiam suam eo nomine accomodare: quod ad cuiusdam traditionis vicem accedit. Itaque non diutius manet societas, quam dum in eodem consensu perseverant. Quod si alter nuncium remiserit, societas ipsa statim solvit. Id ipsum dicendum est in mandato: quod si suscipit, statim curam in eo aliquam adhibere videtur et ipsa opera sua quod recipit, praestare.

93 I. BirocCHI, op. cit., p. 119.

94 I. Birocchi, op. cit., p. 98, M. Diesselhorst, Die Lehre von Hugo Grotius vom Versprechen, Köln-Graz 1959, pp. 30-34.

95 Cfr. F. Wieacker, 'Contractus' und 'Obligatio' im Naturrecht zwischen Spätscholastik und Aufklärung, [in:] La seconda scolastica nella formazione del diritto privato moderno, ed. P. Grossi, Milano 1973, p. 227. 
dimostrato in maniera convincente in dottrina ${ }^{96}$. In conformità con i suoi predecessori egli fa dipendere la forza vincolante della promessa dalla volontà del promittente di obbligarsi nei confronti di un altro, ossia dalla sua decisione in tal senso. Fondamentale in tale prospettiva è la determinazione del momento, in cui una tale decisione viene raggiunta. Dagli scolastici, Grozio prende la distinzione del processo decisivo in tre fasi: al progetto iniziale di fare qualcosa per un altro, propositum $^{97}$, si aggiunge la decisione di farlo, dichiarata con i segni appropriati, policitatio (seconda tappa) ${ }^{98}$, mancando ancora l'intenzione di concedere al beneficiario il diritto di eseguirlo. Quest'ultima viene aggiunta nella terza fase, così completando la promessa ${ }^{99}$. La distinzione tra la seconda e la terza fase si spiega in riferimento al pensiero di De Molina, per il quale il conferimento del diritto al promissario era cruciale per rendere la promessa vincolante non solo moralmente, ma anche giuridicamente, ossia iure naturali. Nella prospettiva del giurista spagnolo la volontà del promittente era sufficiente anche a questo fine. Grozio però si distacca da De Molina proprio in questo punto, ritenendo, in concordanza con Lessius, che il promissario non possa acquisire il diritto alla prestazione senza prima aver accettato la promessa ${ }^{100}$. La promessa diventa quindi vincolante solo con l'accettazione da parte del

96 M. Diesselhorst, op. cit., pp. 4-20, F. Wieacker, op. cit., pp. 232-233.

97 H. Grotius, De iure belli ac pacis, II, XI \$2: Primus gradus est assertio explicans de futuro animum, qui nunc est : et ad hanc, ut vitio careat, requiritur veritas cogitationis pro tempore praesenti, non autem ut in ea cogitatione perseveretur. Habet autem animus humanus non tantum naturalem potentiam mutandi consilium, sed et ius.

98 H. Grotius, op. cit., II, XI $₫ 3$ : Secundus gradus est, cum voluntas se ipsam pro futuro determinat, cum signo sufficiente ad indicandam perseverandi necessitatem. Et haec pollicitatio dici potest (...).

99 H. Grotius, op. cit. II, XI $\$ 4$ : Tertius gradus est, ubi ad determinationem talem accedit signum volendi jus proprium alteri conferre (...)" cfr. M. DiesselHORst, op. cit., pp. $47-50$

100 H. Grotius, op. cit., II, XI $₫ 14$ : Ut tamen promissio ius transferat, acceptatio hic non minus quam in dominii translatione requiritur, ita tamen ut hic quoque praecedens rogatio durare intelligatur, ac vim habere acceptationis". Anche se Grozio non cita esplicitamente Lessius, il suo argomento è sufficientemente affine per supporre la dipendenza dal giurista scolastico. Cfr. M. Diesselhorst, op. cit. pp.111-112. 
promissario. L'argomento di Lessius poggiava sull'analogia tra il pactum obbligatorio e il trasferimento della proprietà, che non si può verificare senza la volontà dell'acquirente ${ }^{101}$. Grozio però fa un passo avanti, spiegando che il promittente trasferisce al promissario una parte della propria libertà, cioè quella che concerne il comportamento promesso ${ }^{102}$. Così egli offre una spiegazione teorica della struttura dell'obbligazione, in quanto diritto del creditore a un comportamento futuro e quindi a una particella della libertà del debitore. Fino a che punto Grozio condivida la convinzione dei teologi morali sulla capacità della volontà umana di vincolarsi pro futuro, lo dimostra però il fatto che egli riconosca il dovere morale di attenersi pure alle promesse non ancora accettate, cioè a partire dalla seconda fasi del processo decisivo. L'obbligo in questione, anche se non genera il diritto da parte del promissario, sussiste moralmente, in quanto fondato sulla costanza del carattere, necessaria per essere affidabili: Multis enim casibus evenit, ut obligatio sit in nobis, et nullum jus in alio; sicut in debito misericordiae et gratiae reponendae apparet, quibus simile est hoc debitum constantiae et fidelitatis ${ }^{103}$.

L'innovazione più importante di Grozio consiste però, nel cambiamento del quadro generale che fornisce le basi teoriche per la sua difesa della libertà contrattuale ${ }^{104}$. Questa nuova impostazione

101 Il contratto come veicolo per il trasferimento dei diritti di proprietà è il concetto standard del contratto comune per gli scolastici. Perciò essi considerano la libertà contrattuale come dipendente dalla libertà del dominus di disporre dei propri beni. Per Lessius la libertà di disporre della proprietà è il segno della proprietà stessa. Se si può trasferire la proprietà si possono trasferire anche i diritti, relativi a questa proprietà. Cfr. W. Decock, op. cit., pp. 165-167.

102 H. Grotius, op. cit. II, XI $\$ 4$ : quae perfecta promissio similem habet effectum qualem alienatio dominii. Est enim aut via ad alienationem rei aut alientio particulae nostrae libertatis. Cfr. F. WIEACKer, op. cit., pp. 228-229.

103 H. Grotius, op. cit., II, XI $\$ 3$. Egli continua dicendo che in base di una tale pollicitatio il promittente non può essere costretto alla prestazione: Itaque ex tali pollicitatione res pollicitantis retineri, aut is ipse qui pollicitatus est ad implendam fidem cogi jure naturali non poterit.

${ }^{104}$ Cfr. F. WieAcker, op. cit., p. 225: "Aber die wichtigste differentia specifica zur Tradition ist die Überführung der gesamten Problemmasse in einen neuen ideologischen Kontext. Nicht die Fragen und die Lösungen haben sich gewandelt, aber ihr ,Stellenwert', und die Intentionen, welche die neuen Autoren verfolgen: Grotius den Aufbau eines 
emerge dalla polemica di Grozio contro Connan: l'argomento principale del giusnaturalista olandese punta sui accordi internazionali che non possono essere vincolanti né in virtù della loro forma (la quale manca in quei casi, trattandosi dei ordinamenti giuridici diversi), né in base della prestazione effettuata da una delle parti ${ }^{105}$. Più importante ancora sembra però l'argomentazione svolta nei Prologomena al De iure belli ac pacis. Grozio sostiene qui che la negazione dell'obbligatorietà degli accordi informali toglierebbe le basi all'esistenza della società stessa, e di conseguenza anche degli ordinamenti di diritto positivo, essendo questi fondate sull'accordo, esplicito o perlomeno tacito, tra gli uomini che si radunano in una determinata società. Siccome l'accordo in questione fonda, e quindi precede, la società e il suo diritto, la sua forma non può essere determinata dal diritto positivo; come spiega Grozio: "obbedire ai patta è una regola del diritto naturale, perché era necessario che i uomini avessero un qualche metodo di obbligarsi a vicenda, e nessun'altro metodo naturale si può concepire"106. La regola pacta sunt servanda si rivela dunque una sorta di condizione che rende possibile l'esistenza della società stessa ${ }^{107}$. Questo modo di pensare, diventerà ancora più pregnante nel pensiero di Hobbes, e nelle teorie successive del contratto sociale. Certo, una tale argomentazione non esclude di per se la possibilità di limitare successivamente la libertà

interkonfessionellen Völkerrechts in der geweiteten Welt des Entdeckungszeitalters, (...)".

105 H. Grotius, op. cit., II, XI $\$ 1$ : Verum haec sententia, ita generaliter ut ab ipso effertur accepta, consistere non potest. Primum enim sequitur inde inter reges et populos diversos, pactorum quamdiu nihil ex iis praestitum est, vim esse nullam, praesertim iis in locis ubi nulla certa forma federum aut sponsionum reperta est.

106 H. Grotius, op. cit., Prologomena, \$15: Deinde vero, cum juris naturae sit stare pactis (necessarius enim erat inter homines aliquis se obligandi modus, neque vero alius modus naturalis fingi potest) ab hoc ipso fonte jura civilia fluxerunt. Nam qui se coetui alicui aggregaverant, aut hominibusque subjecerant, hi aut expresse promiserant, aut ex negotii natura tacite promississe debebat intelligi, secuturos se id quod aut coetus pars major aut hi quibus delata potestas erat constituissent.

107 F. WiEACKER, op. cit., pp. 225-226 giustamente sottolinea il ruolo del contratto e dell'obbligazione come "Schlüssymbole für die Begründung der natürrechtlichen Rechtsordnung der consocitatio humana selbst”. 
contrattuale, introducendo p.e. l'obbligo di forma nell'ambito dei diritti positivi, ma considerando l'importanza degli accordi che dovevano per forza rimanere informali - come quelli, fondatrici della società, oppure quelli internazionali -, tale limitazione doveva presentarsi come incongruente, o perfino paradossale.

Un altro aspetto dell'impostazione groziana che la distingue dalle teorie degli scolastici, consiste nella secolarizzazione della sua argomentazione. Come si è visto, nella teologia morale l'argomento principale, sul quale poggiava l'obbligatorietà dei pacta iure naturali era l'idea che la loro violazione consistesse in un peccato, e non in uno qualsiasi, ma addirittura in uno mortale. Il postulato di armonizzare il diritto positivo con quello naturale, e di conseguenza di estendere l'obbligatorietà dei pacta anche a quel primo ordinamento, dipendeva dalla loro convinzione che l'autorità terrestre, lo stato, deve perlomeno contribuire al compito di condurre gli uomini al loro sommo bene, e cioè alla salvezza. Non è così per Grozio. Nonostante egli possa anche condividere l'opinione che l'infedeltà alla parola data sia un peccato, a suo parere, il motivo per ritenere i pacta obbligatori risiede altrove, e cioè nella loro funzione come strumento principale di cooperazione sociale. Non a caso, infatti, la regola pacta sunt servanda diventa per lui uno dei cinque principi fondamentali del diritto naturale (accanto a quelli di non interferire con la proprietà altrui, di restituire ad un altro ciò che gli appartiene, di risarcire i danni, e di infliggere le pene a coloro che disturbano l'ordine sociale) ${ }^{108}$. Secolarizzato viene anche il concetto stesso del diritto naturale ${ }^{109}$ : il suo scopo non consiste più nel portare la gente alla salvezza, bensì nell'assicurare il funzionamento migliore

108 H. Grotius, op. cit., Prologomena, $\$ 8$.

109 Come secolarizzazione del concetto del diritto naturale intendo il cambiamento del suo obbiettivo, ossia il fatto che esso viene inteso come lo strumento dell'organizzazione della vita sociale, e non più come il mezzo che porta gli uomini alla salvezza. Questo cambiamento incide sia sul contenuto del diritto naturale: esso comprende soltanto tali precetti che hanno rilevanza per la vita sociale, che sul modo di giustificare questi precetti: essi fanno parte del diritto naturale, proprio in quanto sono ritenuti necessari per il funzionamento della società. Il fatto che Grozio crede nell'esistenza di Dio e ritiene che l'organizzazione razionale della vita sociale sia conforme alla volontà divina non contrasta con la secolarizzazione così intesa. Per 
possibile delle società umane ${ }^{110}$. E proprio perché il diritto naturale in quella visione è l'insieme delle regole più razionali per la vita sociale - tra cui quella di rispettare gli accordi fatti, a prescindere dalla loro forma queste dovrebbero essere recepite anche dagli ordinamenti del diritto positivo. Pare che il contributo più importante di Grozio all'affermazione del principio della libertà contrattuale nel pensiero giuridico moderno risieda proprio in questa secolarizzazione del discorso che lo ha reso più adatto al nuovo contesto storico, sociale e culturale che si è venuto affermando nell'Europa a partire della seconda metà del seicento, cioè quello dell'Illuminismo ${ }^{111}$.

la discussione complessiva del problema cfr. Ch. EDwArDs, The Law of Nature in the Thought of Hugo Grotius, "The Journal of Politics» 32.4/1970, pp. 784-807.

110 Come giustamente osserva W. DECOCK, op. cit., pp. 143-144, nell'impostazione dei teologi morali il diritto naturale non regolava i comportamenti umani nei confronti degli altri uomini - membri della stessa società, ma piuttosto riguardava la sua condizione esistenziale in quanto sottoposto al giudizio ultimo nei confronti di Dio: "This law has not as its chief aim to regulate man's behavior as a member of a particular civil or religious community, but as a man in his naked condition before the ultimate judge of his existence, God." Proprio sotto questo aspetto il diritto naturale degli Illuministi, a partire da Grozio, si distingue radicalmente da quello dei suoi predecessori. Nel Prologomena $\$ 8$ Grozio definisce infatti lo scopo del diritto naturale come mantenimento dell'ordine sociale, consone all'intelligenza umana: Haec vero, quam rudi modo iam expressimus, societatis custodia, humani intelectu conveniens, fons est eius iuris, quod proprie tali nomine appellatur: quo pertinent alieni abstinentia, et si quid alieni habeamus, aut lucri inde fecerimus, restitutio, promissorum implendorum obligatio, damni culpa dati reparatio, et poene inter homines meritum.

111 F. Wieacker, op. cit., p. 225, piuttosto che sulla secolarizzazione del discorso insiste sull'emancipazione della teoria giusnaturalistica di Grozio dalla teologia morale. Occorre tuttavia sottolineare che tale emancipazione dipende proprio dalla secolarizzazione del diritto naturale, il quale nell'impostazione groziana non ha più lo scopo di portare gli uomini alla salvezza, bensì quello di salvaguardare l'ordine sociale razionale. 


\section{LA REGOLA 'PACTA SUNT SERVANDA' E LA NASCITA DELLA LIBERTÀ CONTRATTUALE}

\section{Riassunto}

Che la libertà contrattuale, espressa nel broccardo pacta sunt servanda, fosse diventata un principio pressoché indiscutibile nelle teorie giusnaturalistiche dell'Illuminismo, è conoscenza comune. Le sue radici sono tuttavia molto più profonde, in quanto risalgono al pensiero dei giuscanonisti medievali - i primi sostenitori della forza obbligatoria delle promesse informali. Quello che ha portato al riconoscimento definitivo del principio in questione è stato però un processo lungo e complesso. L'obbiettivo del presente articolo consiste nell'individuare i momenti cruciali di questo sviluppo, al quale hanno contribuito molte correnti intellettuali - dalla canonistica, attraverso la seconda scolastica, fino al giusnaturalismo dell'età dei Lumi. Senza tentare di decidere quale di queste correnti abbia portato il contributo decisivo alla creazione del principio in questione, come ha fatto la letteratura precedente, si propone la tesi che è stata la somma dei detti contributi, ciascuno di pari importanza, a portare all'affermarsi della libertà contrattuale nel pensiero giuridico dell'età moderna. Le presenti considerazioni sono focalizzate sullo sviluppo dei concetti, quali la nozione generale del contratto, il suo rapporto al concetto della promessa, la volontà umana come la fonte dell'obbligatorietà del contratto, nonché la giustificazione morale di tale forza obbligatoria.

\section{REGUŁA 'PACTA SUNT SERVANDA' I POCZĄTKI ZASADY SWOBODY UMÓW}

\section{Streszczenie}

Jak powszechnie wiadomo, swoboda umów awansowała do rangi podstawowej zasady prawa kontraktowego w doktrynach prawnonaturalnych epoki oświecenia. Jej korzenie są jednak znacznie głębsze, sięgają bowiem myśli średniowiecznych kanonistów, którzy jako 
pierwsi głosili tezę o wiążącym charakterze jednostronnych przyrzeczeń, nawet tych nieformalnych. Od tych pierwszych początków do pełnego uznania zasdy swobody umów prowadziła jednak długa droga. Celem przedłożonego artykułu jest ustalenie kluczowych momentów tego rozwoju. Przyczynili się do niego przedstawiciele wielu różnych nurtów myślowych: od wczesnośredniowiecznej kanonistyki, poprzez drugą scholastykę ze szkoły w Salamance, po teorie prawnonaturalne początków oświecenia. Inaczej niż w dotychczasowej literaturze, nie jest intencją autorki ustalenie dokładnego momentu powstania omawianej zasady ani tym bardziej przypisanie jej autorstwa jednemu ze wskazanych nurtów. Zgodnie z proponowaną tezą zasada swobody umów w jej współczesnym kształcie powstała w wyniku interakcji wszystkich tych tradycji, przy czym wkład intelektualny każdej z nich był równie istotny. Artykuł skupia się na historii pojęć, takich jak ogólne pojęcie kontraktu, jego relacja do przyrzeczenia, koncepcja woli jako źródła zobowiązania kontraktowego oraz moralne uzasadnienie mocy wiążącej kontraktów nieformalnych.

\section{The 'PACTA Sunt Servanda' Rule and the Origins of Freedom of Contract}

\section{Summary}

It is generally known that freedom of contract, as expressed by the pacta sunt servanda rule, became an unquestionable principle of contract law in the theories of natural law developed in the Enlightenment. However, the roots of this principle go back much further in time, to the doctrine formulated by the medieval Canonists, who were the first to say that unilateral promises, even informal ones, were binding. Nevertheless, a long process led from these early beginnings to the definitive recognition of the principle. The aim of the present article is to identify the crucial moments in this development, to which many different intellectual traditions contributed: from the doctrine of natural law formulated by the Canonists, through the Second Scholastic teachings pursued at the School of Salamanca, to the theories of natural 
law developed in the early Enlightenment. Unlike the general practice in the literature produced on the subject hitherto, my intention is not to pinpoint the exact time when the principle was created, and still less to ascribe it to any one of these intellectual movements. My argument is that it was only the overall outcome of these contributions, each of them equally important, that led to the recognition of the principle. My article focuses on its conceptual evolution, considering themes such as the creation of the general notion of the contract, its relation to the concept of a promise, the capacity of the human will to bind itself by a promise, and the moral grounds for its binding force.

Parole chiave: consensus; contractus; conventio; pactum; promessa; obbligazione; glossatori; commentatori; seconda scolastica; illuminismo; diritto naturale; libertà contrattuale.

Słowa kluczowe: consensus; contractus; conventio; pactum; przyrzeczenie; zobowiązanie; glosatorzy; komentatorzy; druga scholastyka; oświecenie; prawo naturalne; swoboda umów.

Keywords: consensus; contractus; conventio; pact; promise; obligation; glossators; commentators; the Second Scholastic; the Enlightenment; natural law; freedom of contract.

\section{Bibliography}

Astuti, G., Contratto (diritto intermedio), «ED» 9/1961, p. 759-781.

Birocchi, I., Causa e categoria generale del contratto, Torino 1997.

Deсоск, W., Theologians and Contract Law. The Moral Transformation of the Ius Commune (ca. 1500-1650), Leiden-Boston 2013.

Diesselhorst, M., Die Lehre von Hugo Grotius vom Versprechen, Köln-Graz 1959.

Dilcher, H., Der Typenzwang im mittelalterlichen Vertragsrecht, «ZSS» 77/1960, p. 270-303.

EDwards, Ch., The Law of Nature in the Thought of Hugo Grotius, «The Journal of Politics» 32.4/1970, p. 784-807.

Fedele, P., Considerazioni sull'efficacia dei patti nudi nel diritto canonico, «Annali dell'Università di Macerata» 1937, pp. 115-120.

Gordey, J., The Philosophical Origins of Modern Contact Doctrine, Oxford 1991. 
LANDAu, P., 'Pacta sunt servanda'. Zu den kanonistischen Grundlagen der Privatautonomie, [in] Festschrift Knut Wolfgang Nörr, ed. M. Ascher I, F. EbeL, M. HeCKel, Weimar 2003, p. 457-474.

Nanz, K.P., Die Entstehung des allgemeinen Vertragsbegriffs im 16 bis 18 Jahrhundert, München 1985.

Söllner, A., Die causa in Kondiktionen- und Vertragsrecht des Mittelalters bei den Glossatoren, Kommentatoren und Kanonisten, «ZSS» 77/1960, p. 182-269.

Volante, R., Il sistema contrattuale del diritto comune classico. Struttura dei patti e individuazione del tipo. Glossatori e Ultramonatni, Milano 2001.

Wieacker, F., 'Contractus' und 'Obligatio' im Naturrecht zwischen Spätscholastik und Aufklärung, [in:] La seconda scolastica nella formazione del diritto privato moderno, ed. P. Grossi, Milano 1973, p. 223-239. 